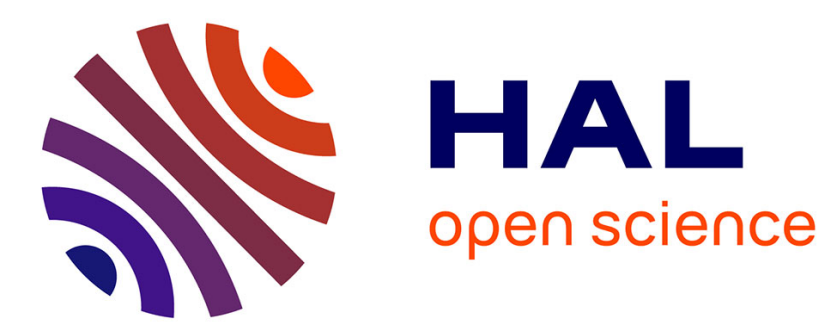

\title{
Working memory impairment in pilots exposed to acute hypobaric hypoxia.
}

Carine Malle, Peggy Quinette, Mickaël Laisney, Cyprien Bourrilhon, Jacqueline Boissin, Béatrice Desgranges, Francis Eustache, Christophe Piérard

\section{- To cite this version:}

Carine Malle, Peggy Quinette, Mickaël Laisney, Cyprien Bourrilhon, Jacqueline Boissin, et al.. Working memory impairment in pilots exposed to acute hypobaric hypoxia.. Aviation, Space, and Environmental Medicine, 2013, 84 (8), pp.773-9. inserm-00835181

\section{HAL Id: inserm-00835181 https://www.hal.inserm.fr/inserm-00835181}

Submitted on 18 Jun 2013

HAL is a multi-disciplinary open access archive for the deposit and dissemination of scientific research documents, whether they are published or not. The documents may come from teaching and research institutions in France or abroad, or from public or private research centers.
L'archive ouverte pluridisciplinaire HAL, est destinée au dépôt et à la diffusion de documents scientifiques de niveau recherche, publiés ou non, émanant des établissements d'enseignement et de recherche français ou étrangers, des laboratoires publics ou privés. 
WORKING MEMORY IMPAIRMENT IN PILOTS EXPOSED TO ACUTE HYPOBARIC HYPOXIA

Carine Malle, M.S. ${ }^{* 1,2,3,4,5}$, Peggy Quinette, Ph.D. ${ }^{* 2,3,4,5}$, MickaËl Laisney, Ph.D. ${ }^{2,3,4,5}$, Cyprien bourrilhon, M.D., Ph.D. ${ }^{1}$, Jacqueline Boissin, M.D. ${ }^{6}$, Beatrice Desgranges, Ph.D. ${ }^{2,3,4,5}$, Francis eustache, Ph.D. ${ }^{2,3,4,5}$, And Christophe PiÉrard, Pharm.D., Ph.D. ${ }^{1}$

*These authors contributed equally to this work

${ }^{1}$ Institut de Recherche Biomédicale des Armées (IRBA), Brétigny-sur-Orge, France

${ }^{2}$ Inserm, U1077, Caen, France

${ }^{3}$ Université de Caen Basse-Normandie, UMR-S1077, Caen, France

${ }^{4}$ École Pratique des Hautes Études, UMR-S1077, Caen, France

${ }^{5}$ CHU de Caen, U1077, Caen, France

${ }^{6}$ Département de Médecine Aéronautique Opérationnelle, Mont de Marsan, France

Address correspondence and reprint requests to: Carine Malle 


\section{ABSTRACT}

Introduction: During an acute hypoxia exposure, an impairment of memory is one of the most frequently reported symptoms, either during hypoxia awareness training of aircrews or after an in-flight hypoxic incident. However, the effects of acute hypoxia on memory have been little studied in laboratory-controlled conditions. Moreover, none of these studies were done in hypobaric conditions. The main aim of this study was to investigate the effects of acute hypobaric hypoxia on working memory (WM). This study was also aimed to find links between physiological measurements and cognitive performance during acute hypoxia exposure. Materials and methods: During hypoxia awareness training, 28 subjects (experimental group) were exposed to a simulated altitude level of $10,000 \mathrm{~m}(31,000 \mathrm{ft})$ in a hypobaric chamber, while 29 subjects (control group) stayed at sea level. WM was assessed in both groups with the Paced Auditory Serial Addition Test (PASAT). Peripheral oxygen saturation $\left(\mathrm{SpO}_{2}\right)$ and heart rate were recorded. Results: WM was strongly impaired in the hypoxic group. One major finding is that hypoxia highly increased the mean error frequency rate. WM performance decreased linearly with hypoxemia, but $\mathrm{SpO}_{2}$ was weakly predictive of PASAT performance and vice versa. Discussion: WM is impaired by acute hypobaric hypoxia. Given the importance of WM in aircraft piloting and its sensitivity to hypoxia, the PASAT, in association with $\mathrm{SpO}_{2}$ and EEG recordings, could improve both hypoxia training and our understanding of the effects of hypoxia on memory.

Keywords: PASAT, altitude, hypobaric chamber, pilot performance, hypoxia training 


\section{INTRODUCTION}

Since the first acute ascent to high altitude, hypoxia has been recognized as one of the most serious single hazard during flight at altitude (16). Nowadays, the hypoxic risk is still a topical question. Indeed, an analysis of U.S Air Force hypoxia incidents from 1976 to 1990 found 656 reported in-flight hypoxic incidents (4).

Because in-flight hypoxic incidents can result in death, hypoxia awareness training in altitude chamber is a mandatory part of aerophysiological training for military aircrews around the world (22). There is evidence that aircrews who have been trained at hypoxia better respond to in-flight hypoxic incidents (11).

Hypoxic symptoms and physiological adaptations to hypoxia have been extensively studied during hypoxia awareness training. It has been shown that they may greatly vary from one subject to another in terms of intensity, speed, and order of appearance. However, the pattern of hypoxic symptoms, currently called "hypoxic signature", tends to be constant in the same subject (10). Physiological and psychological symptoms of acute hypoxia can be roughly classified into 5 types: cardio-respiratory, neurological, behavioural, sensory and cognitive symptoms. According to Woodrow et al.(35), the top 5 symptoms are lightheaded, dizziness, tingling, mental confusion and visual impairment. Smith (27) showed that $42 \%$ and $33 \%$ of 49 training aircrews reported concentration and memory impairments respectively. Despite this finding, few studies have been done to demonstrate memory impairment under hypoxia and the results are not clear. Indeed, Crow and Kelman (6) performed two independent studies. In the first study, the short-term memory task consisted in the recall of a 6-digits sequence after a variable delay (from 2 to $32 \mathrm{~s}$ ), at different altitudes (from 700 to $4,000 \mathrm{~m}$ ). They found a trend for impairment of recall at a simulated altitude of 4,000 m, whatever the delay. However, in a later study performed at these same altitudes, a free-recall task of 10word lists and a scanning task were both found to be preserved. In the scanning task, subjects 
were presented with 2 pages of random text and they were required to scan each page for 5 min, and to mark wherever alphabetically successive pairs (AB, $M N$, etc.) occurred on the page. In a more recent study, Fowler et al. (14) showed an impairment in both a dichotic listening task and a scanning task when these tasks were performed in acute normobaric hypoxia (equivalent to $4,200 \mathrm{~m}$ ). The authors attributed this impairment to a (direct or indirect) slowing of the central executive of working memory (WM). Within human experimental psychology, the term of WM is taken to apply to a limited capacity system that is capable of storing and manipulating information and that is assumed to be an integral part of the human memory system $(1,2)$. During flight, WM is required for aircrew members to simultaneously perform several cognitive tasks (maintaining accurate heading, altitude and airspeed while listening to air traffic controller's speech for example). In case of an in-flight decompression incident, hypoxia could lead to a fatal outcome, by preventing the optimal management of cognitive resource. Thus, to a flight safety point of view, it is essential to investigate attention and WM functioning under hypoxic conditions. Surprisingly, the investigation of WM during an acute hypobaric hypoxic exposure in an altitude chamber (as it can be encountered by pilots during in-flight hypoxic incidents) has not been performed yet. The aim and the originality of this study were to investigate in young pilots the effects of acute hypobaric hypoxia on WM, during hypoxia awareness training. This study was also aimed to find links between physiological measurements and cognitive performance.

\section{MATERIALS AND METHODS}

\section{Subjects}

The study was performed during French Armed Forces aircrews' hypoxia awareness training at the Département de Médecine Aéronautique Opérationnelle (DMAO) in Mont de Marsan, France. Fifty-seven healthy male pilots participated to this study. All were non-smokers and 
right-handed. Pilots were randomized into a control group of 29 subjects, who were not exposed to hypoxia, and into a hypoxic group of 28 subjects. Both groups were matched in age $(23.9 \pm 2.8$ years in the control group vs. $23.9 \pm 1.7$ years in the hypoxic group; $\mathrm{t}(45)=$ $0.14, p=0.89)$, school level $(13.8 \pm 1.6$ years in the control group vs. $14.5 \pm 2$ years in the hypoxic group; $\mathrm{t}(45)=1.3 ; \mathrm{p}=0.20)$, mean sleep duration per night $(7.4 \pm 0.6 \mathrm{~h}$ in the control group vs. $7.5 \pm 0.7 \mathrm{~h}$ in the hypoxic group; $\mathrm{t}(45)=0.77 ; \mathrm{p}=0.44)$, trait anxiety score $(30.6 \pm$ 7.7 in the control group vs. $31.4 \pm 8.3$ in the hypoxic group; $t(45)=0.3 ; p=0.77$ ) and state anxiety score $(31.5 \pm 8.8$ in the control group vs. $34.4 \pm 8.5$ in the hypoxic group; $t(45)=$ 1.04; $\mathrm{p}=0.30$ ). Trait and state anxiety were assessed with the State-Trait Anxiety Inventory (STAI, (28)). The study protocol followed the tenets of the Declaration of Helsinki (34) and was approved in advance by the ethic committee of the Institut de Médecine Aérospatiale du Service de Santé des Armées (IMASSA), France. Each subject was briefed in details and provided written informed consent before participating.

\section{Equipment}

Acute hypoxia was induced with a hypobaric chamber (Sapratin, Bobigny, FRANCE).

Arterial blood oxygen saturation $\left(\mathrm{SpO}_{2}\right)$ and heart rate $(\mathrm{HR})$ were continuously measured by pulse oximetry (Nellcor N395, Covidien-Nellcor ${ }^{\mathrm{TM}}$, Boulder, USA). The pulse oximetry sensor was placed on the subject's forefinger. The sampling frequency was $256 \mathrm{~Hz}$. The signal was recorded on a BIOPAC acquisition chain (BIOPAC Systems, Goleta, California, USA).

EEG and ECG data were only used for medical supervision. 


\section{Design}

To avoid between-group differences in stress level, control and hypoxic groups were placed in similar conditions. At each (control or hypoxic) session, 4 subjects at a time took their places in the hypobaric chamber. During control sessions, the chamber's door remained open. As a consequence, subjects knew that they were not exposed to hypoxia.

The standard hypoxia training profile was chosen for the study $(22,23)$. It consists in: 1$)$ a 45 min denitrogenation phase; 2) an ascent to 9,500 $\mathrm{m}(750 \mathrm{~m} / \mathrm{min}) ; 3)$ hypoxia exposure (remove from oxygen supply one at a time); 4) a return to ground level (750 m / min). Hypoxic exposure stop criteria were: subject's demand, major behavior disturbance (e.g. incoherent speech), cardiac rhythm disorder (evidenced on the ECG), cerebral delta waves appearance (evidenced on the EEG) and $\mathrm{SpO}_{2}$ lower than 60\%. This profile took about 90 min, during which all volunteers received pure oxygen except during hypoxia exposure. The time between $100 \% \mathrm{O}_{2}$ removal and $100 \% \mathrm{O}_{2}$ restoration was defined as Time of Useful Consciousness (TUC) (3). Working memory was assessed during hypoxia exposure.

\section{Procedure}

The WM task consisted of a modified version of the Paced Auditory Serial Addition Task (PASAT) $(15,19)$ (Figure 1). The PASAT is one of the tests most frequently used by neuropsychologists to assess attentional processing and WM. Administration of the PASAT involves presenting a series of single digit numbers where the two most recent digits must be summed. For example, if the digits ' 3 ', ' 6 ' and ' 2 ' were presented, the participant would respond with the correct sums, which are ' 9 ' and then ' 8 '. The participant must respond prior to the presentation of the next digit ( $4 \mathrm{~s}$ later) for a response to be scored as correct. The PASAT is composed of 60 stimuli (244 s). 
Errors were categorized into 3 types: omissions (no response), suppression failures (i.e. adding the digit to the sum of the last addition rather than to the last heard digit) and miscalculations (other errors). We also analysed strings of correct responses (three-or-moreconsecutive correct responses) and strings of errors (three-or-more-consecutive errors). For hypoxic sessions, the PASAT began at 9,500 m, 30 seconds before the induction of hypoxia, and it ended at the same time than the hypoxic exposure. The first minute of the test was not taken into account in the analysis because subjects were disturbed by the beginning of hypoxia exposure.

In order to study the temporal change in performance during acute hypoxia exposure, the percentage of correct responses as a function of time was analysed by dividing the test into 20-second intervals (60-80 s, 80-100 s, etc.). The mean delay (in s) between errors was also calculated.

In order to study the relationship between $\mathrm{SpO}_{2}$ and cognitive performance, the percentage of correct responses as a function of $\mathrm{SpO}_{2}$ was analysed by dividing the test into $5 \% \mathrm{SpO}_{2}$ intervals (100-95\%, 95-90\%, etc.). 


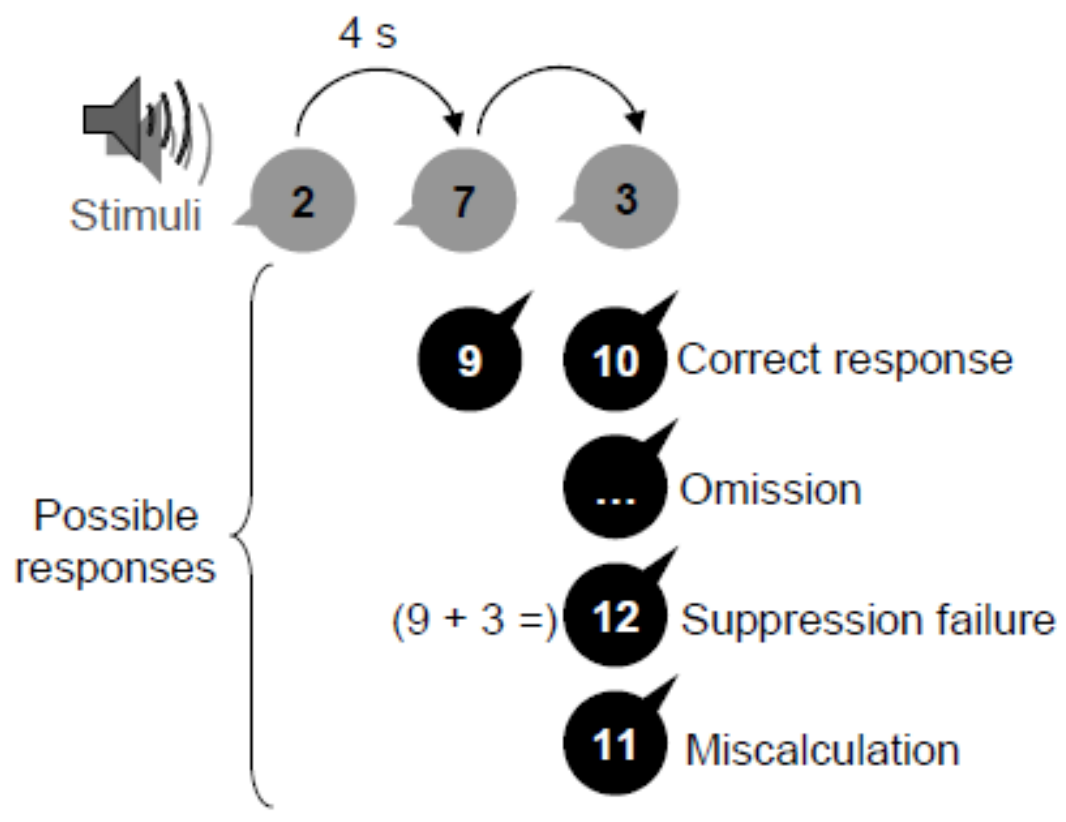

Fig.1. PASAT administration and scoring

Grey bubbles $=$ auditory stimulus, Black bubbles = possible subject's responses

\section{Statistical analysis}

Data analysis was performed using SigmaPlot (SigmaPlot 11.0, Systat Software Inc., San Jose, California, USA). PASAT performance was analysed using one-way and two-way ANOVAs. We checked the variability of means using a normality test (Shapiro-Wilk test). In case of normality test's failure, a one-way or a two-way ANOVA on ranks (Kruskal-Wallis test) was performed. In case of a significant interaction between group and variable, a Tukey post-hoc test was then performed to obtain between-group comparisons. Physiological data were studied with repeated-measure-one-way ANOVAs (within the hypoxic group) and twoway ANOVAs. The correlation coefficient between $\mathrm{WM}$ performance and $\mathrm{SpO}_{2}$ was calculated using a Spearman's correlation test. A p-value $<0.05$ was deemed to be statistically significant. Data are presented as mean \pm standard error of the mean (SEM). 


\section{RESULTS}

\section{Physiological parameters}

Main results are summarized in Table I.

First of all, the mean TUC was $156 \pm 7 \mathrm{~s}$.

Like Barak et al. (3), we divided each hypoxic subject's desaturation curve into 4 phases (Figure 2) : i) the control phase, at $9,500 \mathrm{~m}$, before the beginning of the memory task (this 120 s phase begins $180 \mathrm{~s}$ before the memory task and ends $60 \mathrm{~s}$ before the memory task); ii) the desaturation delay phase, which was the time between $100 \% \mathrm{O}_{2}$ removal and the beginning of the decrease in $\mathrm{SpO}_{2}\left(2 \% \mathrm{SpO}_{2}\right.$ decrease $)$; iii) the desaturation phase, i.e. the period of time between the beginning of decrease in $\mathrm{SpO}_{2}$ and the end of hypoxia exposure and iv) the recovery delay phase, which is the interval between $100 \% \mathrm{O}_{2}$ restoration and the increase in $\mathrm{SpO}_{2}$. In order to perform between-group comparisons, the mean duration of each phase in the hypoxic group was used to define equivalent phases in the control group.

During the control phase, mean $\mathrm{SpO}_{2}(\mathrm{H}(1)=16.44 ; \mathrm{p}<0.001)$ and mean $\mathrm{HR}(\mathrm{F}(1,27)=4.76$; $\mathrm{p}=0.04)$ were higher in the hypoxic group than in the control group.

The desaturation delay phase lasted $49 \pm 3$ s. During this phase, mean $\mathrm{SpO}_{2}(\mathrm{H}(1)=9.78 ; \mathrm{p}=$ 0.07) and mean $\mathrm{HR}(\mathrm{F}(1,27)=3.55 ; \mathrm{p}=0.07)$ became equivalent in both groups. $\mathrm{HR}$ increased in both groups but the increase was higher in the hypoxic group $(\mathrm{F}(1,27)=15.14$; $\mathrm{p}$ $<0.001)$.

The desaturation phase lasted $107 \pm 11$ s. Mean $\mathrm{SpO}_{2}$ at stop was $64.2 \pm 1.0 \%$, which corresponds to a mean decrease of $-35.6 \pm 1.0 \%$. Mean HR was higher in the hypoxic group $(\mathrm{F}(1,27)=33.01 ; \mathrm{p}<0.001)$. During this phase, HR increased in the hypoxic group whereas it decreased in the control group $(\mathrm{F}(1,27)=17.83 ; \mathrm{p}<0.001)$.

During the recovery delay phase, the $\mathrm{SpO}_{2}$ reached a minimum value of $60.1 \pm 1.1 \%$ in the hypoxic group. The mean decrease in $\mathrm{SpO}_{2}$ during this phase was $-5.1 \pm 0.7 \%$ in the hypoxic 
group (significantly different from the control group; $\mathrm{H}(1)=13.34 ; \mathrm{p}<0.001$ ). Mean HR was still higher in the hypoxic group $(\mathrm{F}(1,27)=32.81 ; \mathrm{p}<0.001)$. During this phase, mean HR decreased in both groups but the drop was significantly higher in the hypoxic group $(\mathrm{H}(1)=$ $14.84 ; \mathrm{p}<0.001)$.

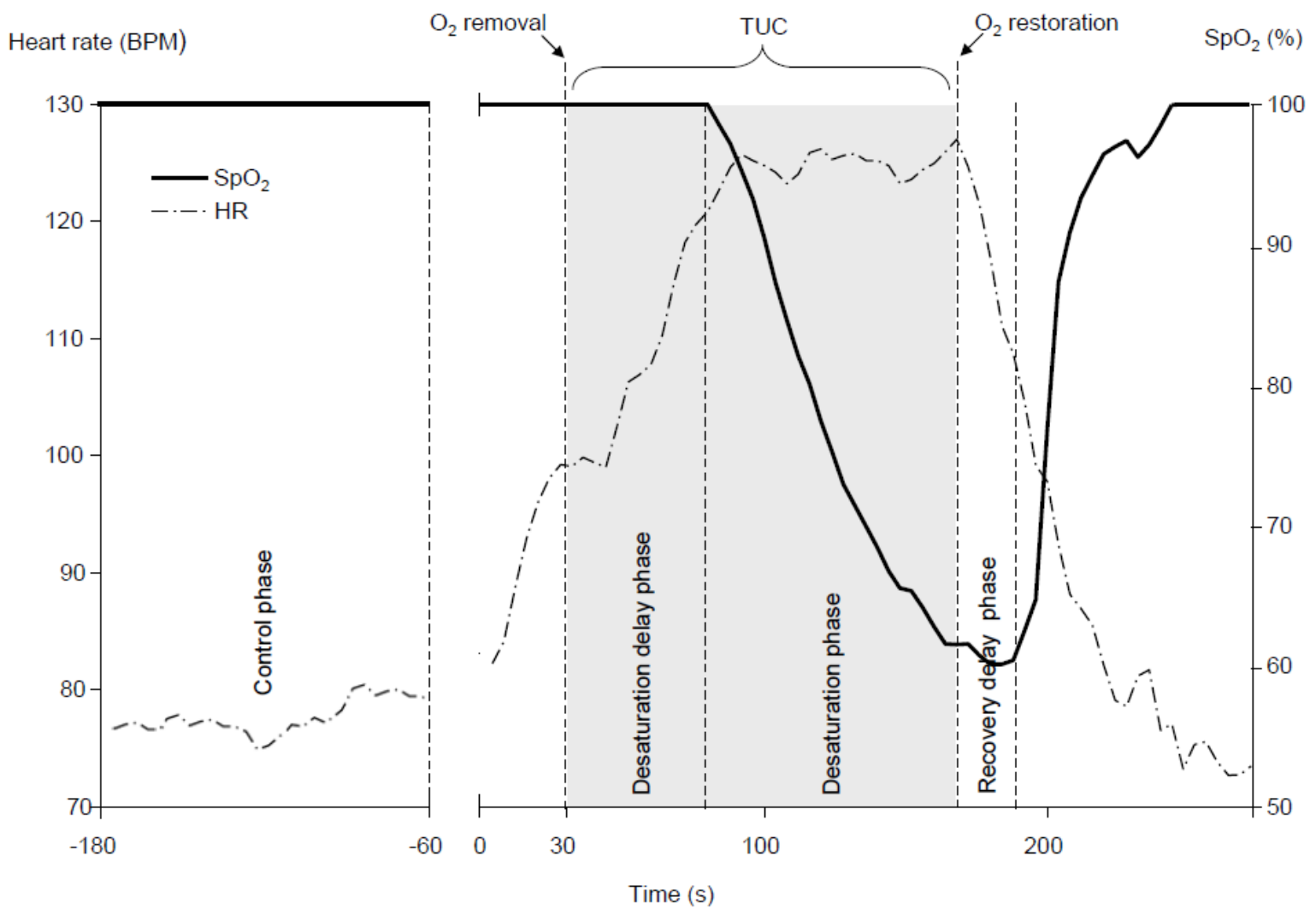

Fig. 2. Phases of the desaturation curve during acute hypoxia exposure.

Solid line $=\mathrm{SpO}_{2}$, dash-dot line $=$ heart rate, grey-shaded area $=$ Time of Useful Consciousness (TUC) 
Table I. Physiological parameters during phases of acute hypoxia exposure

\begin{tabular}{|c|c|c|c|}
\hline Parameters & Control group & Hypoxic group & $\mathbf{p}$ \\
\hline \multicolumn{4}{|c|}{ Control phase } \\
\hline mean $\mathrm{SpO}_{2}(\%)$ & $98.1 \pm 0.2$ & $99.8 \pm 0.1$ & $<0.001$ \\
\hline mean HR (BPM) & $76 \pm 3$ & $87 \pm 3$ & 0.04 \\
\hline \multicolumn{4}{|c|}{ Desaturation delay phase } \\
\hline mean $\mathrm{SpO}_{2}(\%)$ & $98.6 \pm 0.3$ & $99.8 \pm 0.1$ & 0.07 \\
\hline mean HR (BPM) & $81 \pm 5$ & $104 \pm 4$ & 0.07 \\
\hline HR variation (BPM) & $5 \pm 2$ & $17 \pm 2$ & $<0.001$ \\
\hline \multicolumn{4}{|c|}{ Desaturation phase } \\
\hline mean $\mathrm{SpO}_{2}(\%)$ & $98.9 \pm 0.3$ & $79.2 \pm 1.0$ & $<0.001$ \\
\hline mean HR (BPM) & $81 \pm 5$ & $115 \pm 4$ & $<0.001$ \\
\hline $\mathrm{SpO}_{2}$ variation (\%) & $-0.3 \pm 0.3$ & $-35.6 \pm 1.0$ & $<0.001$ \\
\hline HR variation (BPM) & $-5 \pm 3$ & $11 \pm 3$ & $<0.001$ \\
\hline
\end{tabular}

Recovery delay phase

$\begin{array}{crlrl}\text { mean } \mathrm{HR}(\mathrm{BPM}) & 77 & \pm 5 & 109 \pm 3 & <0.001 \\ \mathrm{SpO}_{2} \text { variation (\%) } & -0.2 & \pm 0.3 & -5.1 \pm 0.7 & <0.001 \\ \mathrm{HR} \text { variation (BPM) } & -5 & \pm 1 & -22 \pm 2 & <0.001 \\ \operatorname{min~} \mathrm{SpO}_{2}(\%) & 98.7 & \pm 0.3 & 60.1 \pm 1.1 & <0.001\end{array}$

\section{Working memory task}

Main results are summarized in Table II.

A global analysis shows that the hypoxic group had a significantly lower correct responses percentage $(\mathrm{H}(1)=35.01 ; \mathrm{p}<0.001)$.

The mean delay between errors was twice shorter in the hypoxic group $(\mathrm{H}(1)=14.61 ; \mathrm{p}<$ $0.001)$. 
The hypoxic group made more omissions $(\mathrm{H}(1)=20.77$; $\mathrm{p}<0.001)$ and more miscalculations $(H(1)=26.81 ; p<0.001)$. However, there was no difference in the percentage of suppression failures $(\mathrm{H}(1)=0.152 ; \mathrm{p}=0.70)$.

Interestingly, the errors pattern was significantly different between groups. While the control group made a majority of suppression failures $(53.0 \pm 5.9 \%)$ and miscalculations $(36.0 \pm 4.7$ $\%)$, as compared to omissions $(10.9 \pm 3.8 \%)$, the hypoxic group made a majority of miscalculations $(55.0 \pm 5.0 \%)$ and omissions $(33.7 \pm 5.4 \%)$, as compared to suppression failures $(11.3 \pm 2.9 \%)$. The proportion of omission is therefore three times higher in the hypoxic group $(\mathrm{H}(1)=22.79 ; \mathrm{p}<0.001)$, while the proportion of suppression failures is almost five times smaller $(H(1)=9.35 ; \mathrm{p}=0.002)$.

There was no between-group difference in the number of strings of correct responses $(\mathrm{H}(1)=$ 0.54; $\mathrm{p}=0.46$ ). However, the longest string of correct responses was shorter in the hypoxic group $(\mathrm{H}(1)=35.54 ; \mathrm{p}<0.001)$. No subject performed string of errors in the control group, whereas they were 18 subjects $(64.3 \%$ of the subjects) in the hypoxic group. These subjects performed $1.9 \pm 0.2$ strings of errors on average.

A temporal analysis shows that the performance was the same in both groups during the desaturation delay phase $(\mathrm{H}(1)=0.58 ; \mathrm{p}=0.45)$. During the desaturation phase, the percentage of correct responses remained stable in the control group $(\mathrm{F}(5,28)=1.55$; $\mathrm{p}=$ $0.18)$, whereas it decreased in the hypoxic group $(\mathrm{F}(5,27)=8.13 ; \mathrm{p}<0.001)$. A betweengroup difference in the percentage of correct responses is noted from the $80-100 \mathrm{~s}$ interval $(H(1)=70.26 ; \mathrm{p}<0.001)$ and it lasted until the end of the task (Figure 3). 


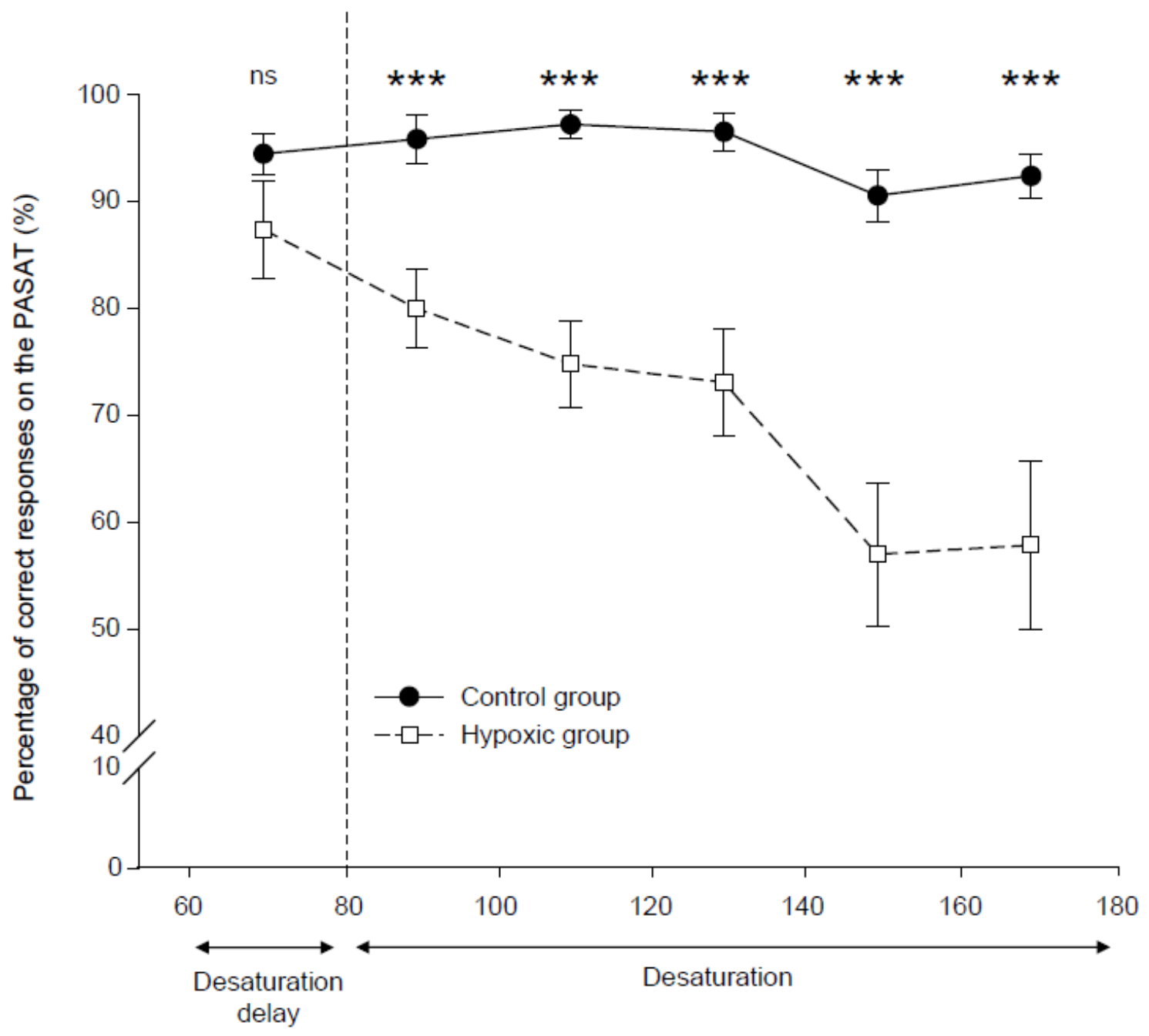

Time (s)

Fig. 3. Evolution of the percentage of correct responses on the PASAT during acute hypoxia exposure.

Mean \pm SEM.

Black circles $=$ control group, white squares $=$ hypoxic group.

ns $=$ not statistically significant, $* * *: p<0.001$ between groups. 
Table II. Main PASAT scores

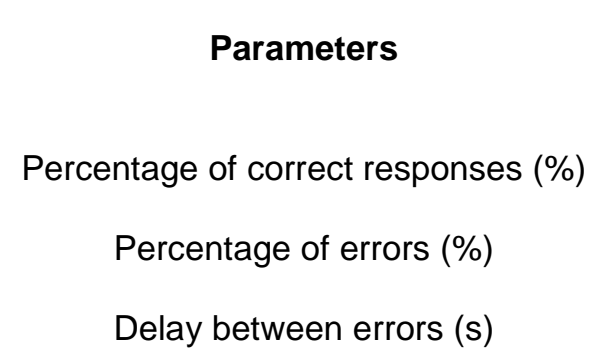

\section{Control Hypoxic}

group group

\section{Errors quantification *}

$\begin{array}{ccccc}\text { Percentage of omissions (\%) } & 0.7 \pm 0.2 & 8.6 \pm 1.3 & <0.001 \\ \text { Percentage of miscalculations (\%) } & 3.1 \pm 0.9 & 18.3 \pm 2.3<0.001 \\ \text { Percentage of suppression failures (\%) } & 3.6 \pm 0.9 & 3.0 \pm 0.7 & 0.7\end{array}$

Errors pattern \$

$\begin{array}{ccccc}\text { Percentage of omissions (\%) } & 10.9 \pm 3.8 & 33.7 \pm 5.4 & <0.001 \\ \text { Percentage of miscalculations (\%) } & 36.0 \pm 4.7 & 55.0 \pm 5.0 & 0.04 \\ \text { Percentage of suppression failures (\%) } & 53.1 \pm 6.2 & 11.3 \pm 2.9 & 0.002\end{array}$

\section{Strings of correct responses}

$\begin{array}{crrr}\text { Number of strings of correct responses } & 2.3 \pm 0.2 & 2.6 \pm 0.3 & 0.46 \\ \text { Length of the longest string of correct responses } & 31.0 \pm 2.2 & 10.5 \pm 1.0<0.001\end{array}$

* The errors quantification corresponds to the percentage of each error type calculated on the total number of responses (correct and incorrect).

\$ The errors pattern corresponds to the percentage of each error type calculated on the number of incorrect responses.

\section{Correlation analysis}

We found that the mean percentage of correct responses decreased linearly as a function of $\mathrm{SpO}_{2}(\mathrm{r}=-0.315 ; \mathrm{p}=0,002)$. However $\mathrm{SpO}_{2}$ is weakly predictive of PASAT performance and vice versa. 


\section{DISCUSSION}

The aim of this study was to investigate the effects of acute hypobaric hypoxia on WM and to find links between physiological measurements and cognitive performance. Our study was done in the framework of classical hypoxia awareness training for aircrews $(9,500 \mathrm{~m})$. The mean TUC was $156 \pm 7 \mathrm{~s}$, which is consistent with previous studies at this altitude (9).

We show that the hypoxic group has a significantly lower correct responses percentage. A major original result concerns the error frequency rate. Hypoxia reduces dramatically the mean delay between errors. Indeed, it is half the length in the hypoxic group. As a consequence, a mean delay between errors of about $40 \mathrm{~s}$ may be considered as "normal" whereas it may become "pathological" below 20 s. Similarly, the longest string of correct responses is three times shorter in the hypoxic group. The analysis of mistakes shows that the hypoxic group makes more omissions and more miscalculations. The errors pattern is also well different, with a hypoxic group preferentially making miscalculations. The mean WM performance decreases linearly with hypoxemia, but there is no correlation between these variables.

In the French Air Force, hypoxia awareness training in hypobaric chamber consists in performing a multitude of different cognitive tasks during a hypoxic exposure of about $150 \mathrm{~s}$ (TUC). None of these tasks have been scientifically validated. Furthermore, the duration and the order of each task are managed by the physician and depend on the participant's resistance to hypoxia. The great variability in administration conditions (low reproducibility) does not allow us to use these data for scientific purposes. It is therefore necessary to choose a validated, sensitive, specific and reproducible test. This task must also fit hypoxia training constraints. Because visual functions are highly sensitive to hypoxia (20), compared to audition (13), an auditory test must be favoured. Its duration must also be in adequacy with the TUC. Finally, the chosen task must upgrade training. Given that WM is mandatory to 
aircraft piloting, a WM task seems a wise choice. Moreover, the use of a unique WM task could improve the detection of hypoxia symptoms by pilots.

The PASAT is a well-known, validated neuropsychological test that meets all these criteria. The major effect of hypoxia on several PASAT parameters, such as the percentage of correct responses and the error frequency rate, demonstrates the high sensitivity of the PASAT to hypoxia. The PASAT has been extensively used in pathologies (29), it is therefore non-specific to hypoxia. However, in a training context (healthy subjects), it allows us to easily differentiate "hypoxic" subjects from control subjects. Indeed, the hypoxic group has a completely different errors pattern, characterized by a great proportion of suppression failures. Strings of errors are specific of the hypoxic group. Moreover, the very rapid effect of hypoxia on PASAT performance $(60-80 \mathrm{~s})$ proves the high sensitivity of the PASAT to hypoxia.

Several studies have reported that the PASAT was highly reproducible (29). As the PASAT is extremely susceptible to practice effects, it is well repeatable as long as there is a sufficient test-retest delay (several months) (29). Reproducibility and repeatability of the PASAT during hypoxia exposure should be determined in later studies.

On a scientific point of view, the PASAT can provide a better understanding of the effects of hypoxia on WM. According to Baddeley's model (2), WM can be divided into the following three subcomponents: (i) the central executive (CE), which is assumed to be an attentional-controlling system ; and two slave systems, namely (ii) the visuospatial sketch pad, which stores and manipulates visual images and spatial sequences and (iii) the phonological loop, which stores and rehearses speech-based information. The PASAT was aimed to assess the $\mathrm{CE}$ functioning. Indeed, it has been shown that, in healthy subjects, bilateral prefrontal cortices, brain regions associated to the CE system $(7,8,24)$, are strongly activated during the PASAT (12). Although the PASAT has been extensively used, in healthy subjects and in pathologies, its analysis underwent few evolutions. Most of the time, the 
assessment of PASAT performance limits itself to the number of correct responses. In some rare studies, the percent correct and the number of errors are added to this score. Wingenfeld et al. (33) introduced new concepts : strings of correct responses and suppression failures. The very different errors pattern of the hypoxic group emphasizes the interest of distinguishing error types. In our point of view, omissions would be due to the inability to face the task because of the attentional demand, while suppression failures would be the result of a specific deficit in inhibition and/or in updating processes. On the other hand, miscalculations would be the consequence of an impairment of the phonological loop (storage component). However, it should be kept in mind that no specific "neuropsychological substrate" was assigned to each error type. In a similar working memory task (running span), Morris and Jones (21) showed that the central executive is involved in digits updating while the phonological loop is involved in the recall of digits. According to this theory, the high proportion of miscalculations and omissions in the hypoxic group may indicate a storage deficit and an attentional overload. More, a deficit in updating, hidden by the high omission rate, cannot be excluded.

During the control phase, mean $\mathrm{SpO}_{2}$ and mean $\mathrm{HR}$ are equivalent in both groups. Indeed, the difference in mean $\mathrm{SpO}_{2}$ disappears when the oxymeter's accuracy $( \pm 2 \%)$ is taken into account. During the desaturation delay phase, there is an increase in HR in both groups and this increase is higher in the hypoxic group. The increase in HR in both groups can be attributed to a PASAT-induced stress effect. Indeed it has been shown that the PASAT is a particularly stressful test (33). The higher increase in the hypoxic group can be explained by a physiological adaptation to hypoxia. As WM is not impaired during this phase, it seems that tachycardia, associated with normal $\mathrm{SpO}_{2}$, leads to an optimal cerebral oxygenation. During the desaturation phase, HR continues to increase in the hypoxic group but fails to compensate the decrease in $\mathrm{SpO}_{2}$. During the recovery delay phase, as $\mathrm{SpO}_{2}$ is still very low, 
reoxygenation caused a marked bradycardia. This phenomenon seems paradoxical since low $\mathrm{SpO}_{2}$ would need to be compensated by tachycardia. One possible mechanism of this "oxygen paradox" is a parasympathetic activation via mechano- and/or chemoreflexes (5). The decrease in HR at the stop of the PASAT being also present in the control group (although lower), a decrease in stress intensity may also participate to this phenomenon.

In the French Air Force, medical supervision of hypoxia awareness training is assured by $\mathrm{SpO}_{2}$, ECG and EEG measurements. A low $\mathrm{SpO}_{2}(<60 \%)$ is the most-frequently-used stop criterion. Pulse oximetry uses the transmission or reflectance of red and infrared light to detect changes in both peripheral tissue volume and blood oxygen carriage. The accuracy of pulse oximetry is limited by assumptions made during calibration of the device. Because these calibration studies are done in volunteers, the calibrated values are limited to those that can be safely induced in healthy subjects, with $\mathrm{SaO}_{2}$ typically falling to between 75 and $80 \%$. The shape of the absorption curve below these values is therefore extrapolated. As a result, there is significant bias that increases with decreasing oxygen saturation (26). The averaging time of the pulse oximeter (form 6 to 20 s) also induces a bias between $\mathrm{SaO}_{2}$ and $\mathrm{SpO}_{2}$ measurements. Pulse oximeters in current use were originally designed for patient monitoring. As a result, signal extraction algorithms may not work well in aviation environment (bright light, motion, vibration and acceleration artifacts) (32). Different probes that are used with a pulse oximeter can also affect the accuracy of $\mathrm{SpO}_{2}$ measurements. Finger probes may be highly sensitive to hypoxia / hypocapnia-induced peripheral vasoconstriction, as compared to ear probes. The response time of ear probes is faster $(15 \pm 3.5 \mathrm{~s})$ than finger probes in response to a decrease in $\mathrm{O}_{2}$ saturation (18). However, the use of ear probes may not be feasible in personnel who are required to wear a helmet. Other limitations of pulse oximetry use in aerospace medicine concern skin pigmentation and nail polish. All these technical limitations could be detrimental 
to pilots, as long as medical supervision of hypoxia training is essentially driven by pulse $\mathrm{SpO}_{2}$ measurement.

These considerations strengthen the interest of monitoring $\mathrm{SpO}_{2}$ in combination with other physiological parameters (such as EEG and ECG). Many studies have shown that cerebral hypoxia induces EEG changes, such as an increase in delta, theta and fast beta-waves and a decrease in alpha activity $(17,25,30,31)$. We therefore think that EEG measurement should be systematically performed during hypoxia training. The occurrence of theta and/or delta waves on EEG could then be used as a major stop criterion. The administration of the PASAT during hypoxia exposure could also bring supplementary indices of cerebral suffering. We propose that a mean delay between errors below $20 \mathrm{~s}$ would be considered as "pathological". Moreover, the occurrence of strings of errors may alert the physician in charge of the medical supervision.

In our study, the low correlation between $\mathrm{SpO}_{2}$ and $\mathrm{WM}$ performance suggests a high individual variability in the cognitive decline with hypoxemia. This result confirms the existence of an individual "hypoxic signature", even at a cognitive level. A major limit of our study is that we did not study the recovery phase (from the end of hypoxia exposure to $100 \%$ $\mathrm{SpO}_{2}$ return). It would be interesting to assess the effect of the increase in $\mathrm{SpO}_{2}$ on $\mathrm{WM}$ performance.

In our point of view, the combination of high-quality physiological measurements $\left(\mathrm{SpO}_{2}\right.$ and EEG) and a suitable cognitive task (like the PASAT) could improve both hypoxia training and our understanding of the effects of hypoxia on memory. 


\section{ACKNOWLEDGMENTS}

We would like to thank the many co-workers who contributed to this work, and all who have offered advice and assistance. In particularly, we would like to thank Mr. Béracochéa Daniel, Mr. Colin Philippe, Mrs. Delmas Vanessa, Mr. Langrume Christophe, Mrs. Liscia Pierrette, Mr. Samtmann Sébastien, Mr. Tronche Christophe, Mr. Van Beers Pascal and all the military nurses of the Département de Médecine Aéronautique Opérationnelle for their technical assistance. 


\section{REFERENCES}

1. $\quad$ Baddeley A. Working memory. Science. 1992 Jan 31;255(5044):556-9.

2. Baddeley AD, Hitch, G.J.L Working Memory. In: Bower GA, editor. The psychology of learning and motivation: advances in research and theory. New York: Academic Press; 1974. p. 47-89.

3. Barak Y, David D, Keselbrener L, Akselrod S. Autonomic response to hypobaric hypoxia assessed by time-dependent frequency decomposition of heart rate. Aviat Space Environ Med. 2001 Nov;72(11):992-1000.

4. Cable GG. In-flight hypoxia incidents in military aircraft: causes and implications for training. Aviat Space Environ Med. 2003 Feb;74(2):169-72.

5. Campagna JA, Carter C. Clinical relevance of the Bezold-Jarisch reflex. Anesthesiology. 2003 May;98(5):1250-60.

6. Crow TJ, Kelman GR. Effect of mild acute hypoxia on human short-term memory. Br J Anaesth. 1971 Jun;43(6):548-52.

7. D'Esposito M, Detre JA, Alsop DC, Shin RK, Atlas S, Grossman M. The neural basis of the central executive system of working memory. Nature. 1995 Nov 16;378(6554):279-81.

8. D'Esposito M, Postle BR, Rypma B. Prefrontal cortical contributions to working memory: evidence from event-related fMRI studies. Exp Brain Res. 2000 Jul;133(1):3-11.

9. DeHart RL, Davis JR. Fundamentals of Aerospace Medicine, 3rd Edition. United States : Lippincott Williams \& Wilkins ; 2002.

10. Ernsting J, Sharp G, Harding R. Hypoxia and hyperventialtion. In : Ernsting J, King P Aviation Medicine, 2nd ed. Oxford: Butterworth Heinemann; 1988. p. 45-59.

11. Files DS, Webb JT, Pilmanis AA. Depressurization in military aircraft: rates, rapidity, and health effects for 1055 incidents. Aviat Space Environ Med. 2005 Jun;76(6):523-9. 
12. Forn C, Barros-Loscertales A, Escudero J, Belloch V, Campos S, Parcet MA, et al. Cortical reorganization during PASAT task in MS patients with preserved working memory functions. Neuroimage. 2006 Jun;31(2):686-91.

13. Fowler B, Grant A. Hearing thresholds under acute hypoxia and relationship to slowing in the auditory modality. Aviat Space Environ Med. 2000 Sep;71(9):946-9.

14. Fowler B, Prlic H, Brabant M. Acute hypoxia fails to influence two aspects of shortterm memory: implications for the source of cognitive deficits. Aviat Space Environ Med. 1994 Jul;65(7):641-5.

15. Gronwall D, Sampson H. The psychological effects of concussion. Auckland: Auckland University Press; 1974.

16. Harding R. Hypoxia and hyperventilation. In : Ernsting J, Nicholson AN, Rainford DJ, eds Aviation Medicine. Oxford: Butterworth Heinemann; 1999. p. 43-58.

17. Kraaier V, van Huffelen AC, Wieneke GH. The hyperventilation-induced ischaemia model in human neuropharmacology: neurophysiological and psychometric studies of aniracetam and 3-OH aniracetam. Eur J Clin Pharmacol. 1989;36(6):605-11.

18. Lindholm P, Blogg SL, Gennser M. Pulse oximetry to detect hypoxemia during apnea: comparison of finger and ear probes. Aviat Space Environ Med. 2007 Aug;78(8):770-3.

19. Mazza S, Pepin JL, Naegele B, Plante J, Deschaux C, Levy P. Most obstructive sleep apnoea patients exhibit vigilance and attention deficits on an extended battery of tests. Eur Respir J. 2005 Jan;25(1):75-80.

20. McFarland R. The effects of altitude on pilot performance. Hannisdahl B, SemJacobsen C, eds Aviation and space medicine Oslo : Universitetsforlaget1969. p. 96-108.

21. Morris N, Jones DM. Habituation to irrelevant speech: effects on a visual short-term memory task. Percept Psychophys. 1990 Mar;47(3):291-7.

22. NATO. STANAG 3114, Aeromedical training of flight personnel. Edition 82006. 
23. NATO. STANAG 7056, Functional requirements for physiological protection during high altitude parachuting operations. Edition 11997.

24. Petrides M, Alivisatos B, Meyer E, Evans AC. Functional activation of the human frontal cortex during the performance of verbal working memory tasks. Proc Natl Acad Sci U S A. 1993 Feb 1;90(3):878-82.

25. Saletu B, Grunberger J, Anderer R. On brain protection of co-dergocrine mesylate (Hydergine) against hypoxic hypoxidosis of different severity: double-blind placebocontrolled quantitative EEG and psychometric studies. International journal of clinical pharmacology, therapy, and toxicology. 1990 Dec;28(12):510-24.

26. Severinghaus JW, Naifeh KH. Accuracy of response of six pulse oximeters to profound hypoxia. Anesthesiology. 1987 Oct;67(4):551-8.

27. Smith AM. Hypoxia symptoms in military aircrew: long-term recall vs. acute experience in training. Aviat Space Environ Med. 2008 Jan;79(1):54-7.

28. Spielberger CD, Gorssuch RL, Lushene PR, Vagg PR, Jacobs GA. Manual for the State-Trait Anxiety Inventory. Consulting Psychologist Press, Inc. ; 1983.

29. Tombaugh TN. A comprehensive review of the Paced Auditory Serial Addition Test (PASAT). Arch Clin Neuropsychol. 2006 Jan;21(1):53-76.

30. van der Post J, Noordzij LA, de Kam ML, Blauw GJ, Cohen AF, van Gerven JM. Evaluation of tests of central nervous system performance after hypoxemia for a model for cognitive impairment. J Psychopharmacol. 2002 Dec;16(4):337-43.

31. Van der Worp HB, Kraaier V, Wieneke GH, Van Huffelen AC. Quantitative EEG during progressive hypocarbia and hypoxia. Hyperventilation-induced EEG changes reconsidered. Electroencephalogr Clin Neurophysiol. 1991 Nov;79(5):335-41.

32. Wagner JL, Ruskin KJ. Pulse oximetry: basic principles and applications in aerospace medicine. Aviat Space Environ Med. 2007 Oct;78(10):973-8. 
33. Wingenfeld SA, Holdwick DJ, Jr., Davis JL, Hunter BB. Normative data on computerized paced auditory serial addition task performance. Clin Neuropsychol. 1999 Aug;13(3):268-73.

34. World Medical Association Declaration of Helsinki: ethical principles for medical research involving human subjects, (2008).

35. Woodrow AD, Webb JT, Wier GS. Recollection of hypoxia symptoms between training events. Aviat Space Environ Med. Dec;82(12):1143-7. 